\title{
LA RENOVACIÓN NEOCLÁSICA DE LA CAPILLA DE LA VERA CRUZ EN EL CONVENTO CASA GRANDE DE SAN FRANCISCO DE SEVILLA
}

\author{
THE NEOCLASSICAL RENOVATION OF THE VERA CRUZ \\ CHAPEL AT THE SAINT FRANCIS CONVENT IN SEVILLE
}

\section{Francisco Amores Martínez}

Asociación Provincial Sevillana de Cronistas e Investigadores Locales, Sevilla. España famoresm@yahoo.es

\begin{abstract}
En el presente trabajo estudiamos la renovación artística de la capilla de la hermandad de la Vera Cruz en el desaparecido convento de San Francisco de Sevilla, llevada a cabo entre los años 1788 y 1840, dando a conocer nuevas obras de diversos artistas del periodo neoclásico.

Palabras clave: Sevilla; convento de San Francisco; Vera Cruz; siglo XVIII; siglo XIX.

We study in this paper the artistic renovation of the Vera Cruz Brotherhood Chapel in the disappeared Saint Francis Convent in Seville, carried out between the years 1788 and 1840, giving to know new works by several artists of the Neoclassical period.

Keywords: Seville; San Francis Convent; Vera Cruz; $18^{\text {th }}$ century; $19^{\text {th }}$ century.
\end{abstract}

Durante seis centurias los franciscanos regentaron en el corazón de la ciudad de Sevilla el mayor complejo monástico de una ciudad ya de por sí plagada de cenobios masculinos y femeninos. La Casa Grande de la orden seráfica, privilegiada durante siglos por las primeras autoridades civiles y eclesiásticas, ocupaba un amplísimo espacio en el que destacaba la iglesia, varios claustros y gran número de capillas que a lo largo del tiempo se fueron cediendo por los frailes a diferentes hermandades y congregaciones o a diversas familias de la nobleza y la burguesía. Una de las corporaciones que se hallaba radicada en el convento de San Francisco era la de la Santísima Vera Cruz, la cual, cuando fue fundada el año 1448, se instaló en una capilla situada junto a la portería, y desde 1478 pasaría a gozar ya en propiedad de otra capilla de mayor tamaño que se hallaba en el 
núcleo más antiguo del convento, el que ocupaban la iglesia y el claustro principal, y que se corresponde aproximadamente con la parte de la actual plaza Nueva que se abre a las calles Granada y Tetuán. La capilla de la Vera Cruz fue objeto desde entonces de sucesivas reformas y ampliaciones, fruto de las donaciones de diversos espacios que para ello le hicieron los frailes, y la anexión de algunas capillas vecinas de patronato privado, espacios con los que se fue ampliando el templo y edificando sus dependencias anexas como sacristía, sala de juntas, almacén e incluso un jardín. De este complejo proceso deben destacarse algunos hitos como la cesión de la capilla de Pedro Melgarejo en 1541, que permitió ensanchar el templo y abrirlo al claustro, la reforma de 1585 dirigida por el arquitecto Asensio de Maeda, o la anexión en 1651 de la capilla que había sido de Alonso Núñez de Arroyo, que hizo posible labrar un nuevo crucero. Todo ello daría como resultado la que sería considerada, más que como capilla, como una segunda iglesia dentro del convento de San Francisco, de la cual se conserva una somera pero elocuente descripción de comienzos del siglo XVIII que nos dice que constaba de una sola nave "grande y muy espaciosa", que contenía en su interior tres altares y dos ricas capillas, y que sus muros se hallaban adornados con numerosas pinturas ${ }^{1}$. Entre estas últimas, que formaban un fastuoso conjunto desintegrado en los sucesos de las primeras décadas del siglo XIX, destacaban catorce lienzos firmados por grandes artistas como Pacheco, Herrera el Viejo o Murillo. En el contexto de las sucesivas reformas de las que fue objeto tan suntuosa capilla, en el presente artículo pretendemos abordar uno de los periodos menos conocidos, el que corresponde a la postrer etapa de su existencia, que abarca las últimas décadas del siglo XVIII y las primeras del XIX, unos años en los que la hermandad de la Vera Cruz promovió un conjunto de realizaciones artísticas que corrieron a cargo de importantes artífices del periodo neoclásico. Nos basaremos para ello en una serie documental que, si bien ciertamente fragmentaria y dispersa, aún se conserva en el archivo de la hermandad, la cual hemos intentado ordenar y exponer de la manera más coherente posible. Debe advertirse que casi todos estos documentos se refieren a obras de arte desaparecidas, lo que no hará posible un análisis más certero de las intervenciones de los diversos artistas, aunque sí una notable contribución al conocimiento de la obra de cada uno de ellos.

${ }^{1}$ Sobre la conformación de la capilla a lo largo de los siglos XVI y XVII véase BERMEJO Y CARBALLO, José: Glorias religiosas de Sevilla. Sevilla, 1882 (ed. Sevi1la, 2013), pp. 407-415; DEL CASTILLO Y UTRILLA, María José: El convento de San Francisco Casa Grande de Sevilla. Sevilla, 1988, pp. 94-98; ÁLVAREZ MORO, María de las Nieves Concepción: Historia y arte en la Hermandad de la Vera Cruz de Sevilla. Sevi1la, 1998, pp. 55-58 y 65-99; y RODA PEÑA, José: "La capilla de la Vera Cruz en el Convento Casa Grande de San Francisco y sus tesoros artísticos", Boletín de las Cofradías de Sevilla, 479, 1999, pp. 51-56. 
Durante la mayor parte del siglo XVIII la hermandad de la Vera Cruz estuvo regida por una junta integrada por destacados miembros de la aristocracia y la alta burguesía hispalense, lo que propició un notable auge en todos los órdenes que también tuvo su reflejo en el ámbito patrimonial. Desde la segunda década de aquella centuria no cesaron las reformas y restauraciones que afectaron tanto a los altares como a las propias andas y enseres que se usaban en la estación penitencial del Jueves Santo. Centrándonos en el periodo que nos ocupa, comenzaremos aportando nuevos datos sobre el retablo de la capilla de la Concepción, la primera del lado del evangelio a los pies de la iglesia. Esta capilla había sido cedida en agosto de 1591 por la cofradía al matrimonio formado por Alonso Chaves Galindo y Juana de Abreu para que en ella labrasen bóveda y retablo, en el cual colocaron una pintura con la representación de la Inmaculada. Pues bien, llegado el año 1714 la hermandad labró un almacén para los pasos al que se accedía por esta capilla, por lo que fue necesario quitar su antiguo retablo, encargándose quince años después uno nuevo al maestro escultor Pedro de Torres $^{2}$, entronizando en el mismo una imagen de la Inmaculada que en 1717 había labrado el escultor Bartolomé García de Santiago ${ }^{3}$. Por nuestra parte podemos añadir que el año 1788 la hermandad decidió acometer el dorado y pintado de este retablo de la Concepción, tarea que llevó a cabo el maestro Pedro Vidal ${ }^{4}$. Debido a la falta de documentación, no podemos asegurar que se tratase del mismo retablo estrenado en 1729 , en cuyo caso resultaría extraño que se hubiese tardado tanto tiempo en dorar, o si por el contrario el mismo había sido sustituido por otro de nueva hechura hacia 1787-1788, algo que nos parece más probable. En este último caso debió tratarse de una obra de medianas proporciones tallada en el estilo tardobarroco que cultivaron los maestros seguidores de Cayetano de Acosta, aunque quizá integrase ya incipientes rasgos de la nueva estética neoclásica que por entonces se empezaba a imponer en la ciudad. Lo cierto es que Pedro Vidal daba recibo de 6.200 reales el día 28 de marzo de 1788 por el "dorado y pintado" de este retablo, según se detalla en el apéndice documental. Hay que señalar que Vidal aparece en la documentación conocida por primera vez como maestro dorador, residente en la collación de San Juan de la Palma, en noviembre del año 1782, fecha en la que se obligaba a pintar, dorar y estofar el nuevo monumento de Semana Santa de la parroquia de la localidad onubense de Aro$c^{5} e^{5}$ y por esas mismas fechas aparece desempeñando destacadas funciones en la hermandad de San Lucas, del gremio de pintores y doradores, siendo uno de los

2 ÁlVAREZ MORO, María de las Nieves Concepción: Historia y arte..., op. cit., p. 90.

Ibidem, p. 86.

${ }^{4}$ AHSVCS (Archivo de la Hermandad de la Santísima Vera Cruz de Sevilla), caja 049.

${ }^{5}$ ROS GONZÁLEZ, Francisco S.: Noticias de escultura (1781-1800). Sevilla, 1999, p. 141. 
principales protagonistas de los últimos y aciagos años de existencia del mismo ${ }^{6}$. Tras una trayectoria profesional que debió ser ascendente y de acreditada solvencia, fue designado maestro dorador del arzobispado de Sevilla en el mes de julio de $1799^{7}$. Volviendo al retablo de la Concepción de la capilla de la Vera Cruz, Álvarez Moro nos informa de que, cuando los invasores franceses ocuparon el convento de San Francisco en 1810, los hermanos de la Vera Cruz resolvieron ceder en calidad de depósito aquel retablo al presbítero José de la Barrera ${ }^{8}$, el cual formaba parte del clero de la vecina parroquia del Sagrario de la catedral hispalense $^{9}$, desconociéndose por el momento el posterior destino de la obra.

En la iglesia de la Vera Cruz había una segunda capilla de patronato particular, frontera a la anterior en el lado de la epístola, y como ocurría con la de la Concepción, ya a finales del siglo XVII la hermandad se había visto obligada a hacerse cargo de su mantenimiento ante la desidia de los herederos de la familia fundadora. Se trataba en este caso de la capilla que la cofradía había cedido en julio de 1591 a Juan Rodríguez de Cartagena y su esposa Bárbara Fernández, quienes encargaron para ella un retablo aquel mismo año al ensamblador Bartolomé Muñoz y al escultor Pedro de la Cueva ${ }^{10}$. De esta obra desaparecida se conserva una interesante descripción que nos brinda el maestro escultor y ensamblador Antonio de Carvajal, con motivo del reconocimiento que le encomendó la hermandad para comprobar su estado, fechada en 24 de julio de 1716, y que por su interés trascribimos aquí: "se compone de un nicho redondo, y de el nicho arriva llega hasta el techo, en cuia coronación de arriva, su cuerpo de Arquitectura, y en medio un Padre Eterno, y a los lados dos frontes ensima de la corniza en que están los Ángeles Sn Miguel y Sn Raphael, y en el nicho principal está la ymagen de nuestra Señora del Rosario; en la bolsura del redor, repartidos en tableros atributos de nra. Señora; en los últimos dos tableros de abajo sobre la Mesa del Altar dos retratos mui antiguos sin letreros; y en la orla del redor diferentes figuras de medio relieve de distintas devociones de a media vara con corta diferencia. Dos columnas en el nicho de nra. Señora y seis pinturas de diferentes santos, y todo lo referido de dho retablo por su mucha antigüedad está de mui mala calidad y

${ }^{6}$ AMORES MARTÍNEZ, Francisco: "El gremio de pintores y su hermandad en la Sevilla del siglo XVIII", Archivo Hispalense, 291-293, 2013, pp. 395-397.

7 AMORES MARTÍNEZ, Francisco: "Artistas y artesanos al servicio de los arzobispos sevillanos. Algunas noticias sobre sus maestros mayores", Anuario de historia de la Iglesia andaluza, IX, 2016, p. 266.

${ }^{8}$ ÁlVAREZ MORO, María de las Nieves Concepción: Historia y arte..., op. cit., p. 45

${ }^{9}$ Del CAStillo Y UTRILla, María José: El convento de San Francisco..., op. cit., p. 113.

${ }^{10}$ LÓPEZ MARTÍNEZ, Celestino: Arquitectos, escultores y pintores vecinos de Sevilla. Sevilla, 1928, pp. 106-107. 
le faltan muchas piezas"11. En base a este informe la hermandad acordó hacer un nuevo retablo, que fue tallado en estilo barroco por el citado maestro Antonio de Carvajal, mientras que la imagen de la Virgen fue renovada también en 1730, siendo obra del ya citado Bartolomé García de Santiago, y finalmente se doró el retablo en 1751 por Juan Moreno ${ }^{12}$.

Pues bien, por razones que no conocemos, cuarenta años más tarde la hermandad decidió acometer la hechura de un nuevo retablo para la Virgen del Rosario, con fondos provenientes de la dotación de Juan Rodríguez de Cartagena. La nueva obra se encomendó a José Gabriel González, aunque también intervinieron otros maestros, como se verá seguidamente. Aunque no hemos localizado el contrato de la obra ni el recibo por su ejecución, todo apunta a que fue el citado González el que se encargó de la misma, porque este maestro presentaba a la hermandad la cuenta de los gastos que había tenido "la colocación del retablo nuevo en la capilla de la Sta. Beracruz", que ascendieron a 1.394 reales, de los cuales 286 correspondían a materiales, 768 a los jornales de los oficiales y 340 a los del propio maestro, especificando que la tarea comenzó el día 11 de agosto y concluyó el 2 de octubre del año $1794^{13}$. Esta misma relación se menciona en la cuenta más amplia que dieron el 31 del mismo mes de octubre los cofrades comisionados para la obra, Manuel Paulín y Vicente Calonge. Es del todo punto razonable pensar que se encargase de la colocación del retablo el mismo maestro que lo había realizado, que no pudo ser otro por tanto que José Gabriel González. El retablo se hallaba concluido a comienzos del mes de agosto, prolongándose su instalación por tiempo de dos meses, realizando las obras de albañilería en el hueco del altar el alarife de la cofradía Manuel Talabán. Por su parte, el maestro tallista Manuel Barrera y Carmona declaraba el mismo día 2 de octubre haber concluido un "repisón" para este retablo ${ }^{14}$, palabra que debe aludir a la mesa del mismo, elemento que fue posteriormente dorado y pintado por Pedro Vidal imitando piedra jaspe ${ }^{15}$. Aunque por desgracia el retablo no ha llegado hasta nues-

${ }^{11}$ AHSVCS, caja 093

12 ÁlVAREZ MORO, María de las Nieves Concepción: Historia y arte..., op. cit., pp. 86 y $89-90$.

13 AHSVCS, caja 087.

${ }^{14}$ Ibidem. "He recibido de los Sres. Dn. Manuel Paulín y Dn Vicente Calonge trescientos veinte reales de vellón por la construcción de un Repisón y composición del Retablo que está a la derecha en la entrada de la Capilla de la Vera Cruz, y para que conste lo firmo en Sevilla a 2 de Mayo de 1794. Manuel Barrera y Carmona [firma]." Aunque este recibo aparece fechado en mayo, todo indica que se trata de un error en su redacción, teniendo en cuenta la fecha de los demás documentos relacionados con la obra.

${ }^{15} \mathrm{Ibid}$. "He recibido del Sr. Dn. Vicente Calonge trescientos y veinte rs. de vellón en plata, valor de el dorado y pintado de Piedra de la Repisa del Retablo de la Virgen del Rosario de la Capilla de la Sta. Vera Cruz, sita en el Combento de N. S. P. Sn. Francisco de esta Ciudad. Sevilla y Octubre 2 de 1794. Pedro Vidal [firma]." 
tros días, el análisis de las escasas obras conservadas de José Gabriel González hace pensar que debió ser de líneas neoclásicas, con dos columnas corintias sosteniendo un entablamento recto y sencillo ático de medio punto, con hornacina central para albergar la imagen de la Virgen del Rosario y dos repisas laterales para las de San Francisco y Santo Domingo, tres tallas que fueron restauradas para la ocasión. En cuanto al material con que se realizó la obra, no puede descartarse que hubiera sido el estuco, ya que González era el mayor especialista en el empleo del mismo que había entonces en Sevilla. Además, cuando en las cuentas se alude a la repisa tallada por el maestro Carmona, los cofrades especificaban que era "de madera", quizá queriendo distinguirla del resto del retablo que no habría sido tallado en el mismo material. Precisamente consta que José Gabriel González, artista autodidacta según el profesor Recio, se declaraba en un documento de aquel mismo año 1794 "maestro arquitecto de tallista y practico en obras de estuco", y en calidad de tal había realizado solo un año antes en ese último material el retablo mayor de la iglesia parroquial de Omnium Sanctorum, aunque también tenía acreditado su dominio de la talla de la madera en la sillería del coro de la iglesia colegial del Salvador, obra de $1790^{16}$. Precisamente, en distintas fases del largo y complejo proceso de ejecución del retablo de Omnium Sanctorum, habían tenido ocasión de participar los mismos tres maestros que colaboraron en el de la Virgen del Rosario de la capilla de la Vera Cruz, González, Barrera y Carmona y Vidal, lo que indica que se trataba de los principales especialistas en su materia que trabajaban entonces en la ciudad hispalense ${ }^{17}$. Ya hemos hecho mención anteriormente a la personalidad del dorador Pedro Vidal, y en cuanto a su amigo Manuel Barrera y Carmona, hay que decir que fue un maestro tallista y arquitecto de retablos cuya fecunda trayectoria se prolongó por espacio de medio siglo, con una primera etapa inserta en el estilo del último barroco y otra ya puramente neoclásica ${ }^{18}$.

${ }^{16}$ RECIO MIR, Álvaro: "El peso inmenso de la historia: neoclasicismo e historicismo", en El retablo sevillano desde sus orígenes a la actualidad. Sevilla, 2009, p. 402; HERRERA GARCÍA, Francisco J.: "Écija como centro artístico. Los tallistas del siglo XVIII", en Actas del II congreso de historia Écija en el siglo XVIII. Écija, 1995, p. 339; ROS GONZÁLEZ, Francisco S.: "El retablo mayor de estuco de la parroquia de Omnium Sanctorum de Sevilla (1791-1793)", Laboratorio de arte, 13, 2010, pp. 153-172; y MARTÍN PRADAS, Antonio: "El conjunto coral de la iglesia colegial y parroquia del Divino Salvador de Sevilla (1512-2003)", Laboratorio de arte, 16, 2003, pp. 238-239.

${ }^{17}$ FERNÁNDEZ GONZÁLEZ, Alberto: "Trazas y proyectos de la iglesia parroquial de Omnium Sanctorum de Sevilla”, Laboratorio de arte, 20, 2007, pp. 203-228.

${ }^{18}$ RODA PEÑA, José: "Manuel Barrera y Carmona, retablista en la Sevilla de Carlos III", Archivo Hispalense, 217, 1988, pp. 197-221; RECIO MIR, Álvaro: "El final del barroco sevillano: Manuel Barrera y Carmona, Blas Molner y el retablo mayor de San Bernardo", Archivo Hispalense, 252, 2000, p. 135; MARÍN FIDALGO, Ana: La iglesia 
El estreno del retablo de la Virgen del Rosario se enmarcaba en un proyecto más amplio de restauración y renovación de la mayor parte de la capilla, que gracias al buen estado de sus arcas acometió la propia hermandad de la Vera Cruz. Así, durante todo el año 1794 se realizaron trabajos de pintura y dorado, así como restauraciones de diverso alcance en pinturas y esculturas. El maestro pintor y dorador Pedro González daba recibo el día 8 de marzo de 375 reales por "estofar los arcos torales y dorarlos de dha Capilla, y renovar los escudos de ellos, y retocar y envarnizar los dos Lampareros", y desde aquella fecha hasta el mes de julio prolongó su trabajo con otras intervenciones menores en la pintura de rejas, puertas, escaños, estantes y pila del bautismo, a la cual dio una capa de aceite, así como una pequeña intervención en el retablo mayor, por todo cual la cofradía le pagó algo más de 400 reales $^{19}$. De este artífice se tienen muy pocas noticias, entre ellas la de que en noviembre de 1797 se titulaba "maestro pintor" y residía en la calle de la Cerrajería ${ }^{20}$. El otro miembro del mismo gremio que fue llamado por la hermandad para colaborar en la renovación de su patrimonio artístico fue Francisco de Morales, quien tras llevar a cabo trabajos menores en la primavera de 1794, por los que cobró mil reales, acometería en diciembre del año siguiente el dorado y pintado de la nueva frontalera que se había hecho para el retablo del altar mayor ${ }^{21}$, cuya autoría no se conoce, aunque cabe pensar que la tallase alguno de los maestros ya mencionados como Manuel Barrera. La hermandad pagó al dorador por su trabajo 150 reales. En cuanto a su personalidad, pensamos que debe identificarse con Francisco de Morales Fariñas, vecino de la collación de San Marcos, que precisamente había dorado en 1778 el retablo mayor de la capilla de los Burgaleses ${ }^{22}$, vecina de la de la Vera Cruz en el convento de San Francisco, el mismo artífice que en febrero del año 1817 sería designado maestro mayor de pintura, dorado y estofado del arzobispado de Sevilla por el prelado Romualdo Mon y Velarde, como culminación de una fructífera carrera ${ }^{23}$. Este proceso restaurador afectó también a otras piezas del patrimonio de la capilla, como los doce grandes blandones o hacheros de madera que se usaban en los cultos solemnes, los cuales fueron primero pintados de verde y plateados por

parroquial de San Andrés de Sevilla. Sevilla, 2007, pp. 213-214; y ROS GONZÁLEZ, Francisco S.: Noticias de escultura ..., op. cit., pp. 129-143.

${ }_{19}$ AHSVCS, caja 077.

${ }^{20}$ ROS GONZÁLEZ, Francisco S.: Noticias de escultura..., op. cit., p. 414.

${ }^{21}$ AHSVCS, caja 077.

${ }^{22}$ CABEZAS GARCÍA, Álvaro: "Algunos datos sobre doradores de la segunda mitad del siglo XVIII en el arzobispado hispalense", Anuario de historia de la Iglesia andaluza, VIII, 2015, p. 307.

${ }_{23}$ AMORES MARTÍNEZ, Francisco: Artistas y artesanos..., op. cit., p. 266. 
Diego Suárez en $1784^{24}$, y posteriormente el año 1800 el escultor José Ximénez tallaría para cada uno de ellos nuevos pedestales, por los cuales percibió 840 rea1 les ${ }^{25}$. También Ximénez sería nombrado años más tarde maestro tallista del arzobispado por el cardenal Cienfuegos ${ }^{26}$.

Los graves daños que la invasión francesa causó al patrimonio artístico de la ciudad tuvieron una significación especial en el caso del convento de San Francisco, en lo que tuvo mucho que ver su ubicación y la ya referida envergadura del complejo monástico. Durante la ocupación extranjera la mayor parte del conjunto pictórico de la capilla fue requisada por las nuevas autoridades y depositada en el Real Alcázar, aunque algunas obras pudieron ser ocultadas en casa de los hermanos, gracias a lo cual se conservan aun en nuestra ciudad en diversos lugares. En cuanto a las imágenes titulares, parece que fueron colocadas provisionalmente en la capilla de San Millán de la iglesia parroquial del Sagrario, y por lo que respecta a los retablos, pudieron salvarse algunos, como el mayor, valiosa obra de Francisco de Barahona del año 1700, que fue depositado en el llamado Hospitalito de San José, propio de la Venerable Orden Tercera y que se encontraba en la calle de los Catalanes, actual de Carlos Cañal. Otros dos fueron entregados en depósito a sendos señores particulares ${ }^{27}$, desconociéndose por el momento el destino final de estas obras de arte. Ya muy diezmada por tanto en su patrimonio, la capilla de la Vera Cruz resultaría gravemente dañada con motivo de un incendio, cuyas causas no se conocen con exactitud, que afectó a la parte septentrional del convento a finales del año 1810. En agosto de 1812 los frailes regresaron a San Francisco, instalándose desde entonces la cofradía de la Vera Cruz en la capilla de los Burgaleses. En cuanto a la capilla de su propiedad, en cabildo celebrado el 2 de febrero del año 1830 se acordó comenzar su reedificación, empezando las obras en el mes de julio, y prolongándose por espacio de más de tres $a_{n}{ }^{28}{ }^{28}$. Ya en 1832 debían estar muy avanzadas, pues en esa fecha la hermandad realizó de nuevo desde allí su estación de penitencia, con nuevos pasos y enseres ${ }^{29}$. Pero no sería hasta dos años más tarde cuando se acometería la imprescindible tarea de realizar nuevos retablos, pues los antiguos del siglo XVIII no volvieron nunca a su primitivo lugar.

El 14 de mayo de 1834 el maestro ensamblador José Mayorga presentaba a los oficiales de la hermandad de la Vera Cruz el pliego de condiciones para

${ }^{24}$ AHSVCS, caja 077. Se trata del padre del también pintor José Suárez Acosta (1765-1800).

${ }^{25}$ Ibidem.

26 AMORES MARTÍNEZ, Francisco: Artistas y artesanos..., op. cit., p. 264.

${ }^{27}$ ÁlVAREZ MORO, María de las Nieves Concepción: Historia y arte..., op. cit., p. 45 .

${ }^{28}$ Ibidem, p. 46.

29 BERMEJO Y CARBALLO, José: Glorias religiosas..., op. cit., p. 417. 
realizar para su capilla tres retablos, uno mayor para el Santísimo Cristo, y otros dos más pequeños para la imagen de la Virgen de las Tristezas, dolorosa titular de la cofradía, y para la Santa Cruz, obligándose a tallarlos en madera de pino de flandes en un plazo de cuatro meses, por un precio total de 4.500 reales pagaderos en tres plazos, y con unas medidas aproximadas de seis metros y medio de alto por cuatro de ancho en el caso del mayor, y de cinco metros de alto y tres de ancho los dos menores ${ }^{30}$. Mayorga era entonces junto con Juan de Astorga el principal retablista activo en Sevilla. Documentado como maestro tallista desde el año $1791^{31}$, su primera obra conocida y una de las pocas conservadas es el retablo mayor de la ermita de la Soledad de Cantillana, obra de notable envergadura de $1793^{32}$, y dos años más tarde labraba en un estilo similar otro para la capilla de Nuestra Señora de los Dolores en la iglesia parroquial de San Bartolomé de Sevilla ${ }^{33}$, que afortunadamente ha llegado también a nuestros días. No ocurrió lo mismo con los retablos colaterales tallados por Mayorga para el presbiterio de la iglesia parroquial de San Pedro de Sevilla en 1823, aunque sí se conservan el sagrario y el manifestador realizados por el mismo artífice un año más tarde para el altar mayor del citado templo ${ }^{34}$. Sabemos también que José Mayorga estuvo matriculado en la sección de arquitectura de la Escuela de Nobles Artes durante tres cursos seguidos entre 1815 y 1818, y más tarde otra vez en el curso $1825-26^{35}$.

Por tanto, cuando en 1834 la hermandad de la Vera Cruz realizaba a Mayorga el importante encargo del conjunto completo de retablos para su reedificada capilla, el artista ya contaba con una amplia experiencia. Las tres obras se hallaban finalizadas en el mes de noviembre, dando recibo su autor de 5.496 reales por las mismas, cantidad en la que se incluía una "composición" del retablo mayor, probablemente un añadido no previsto inicialmente, así como la ejecución de cinco peanas, una para la Virgen y otras cuatro para otros tantos ángeles propiedad de la hermandad que se usaban también en el paso del Señor en la estación del Jueves Santo. Aunque estos tres retablos no se han conservado, contamos con el valioso testimonio de José Bermejo (1817-1888), quien en su juventud alcanzó a conocer la capilla, el cual nos dice que el retablo mayor constaba de dos grandes columnas corintias que sostenían un entablamento coronado por un "medio punto con recuadros", es decir un luneto acasetonado, con hornacina o camarín central donde se veneraba la imagen del Santísimo

\footnotetext{
${ }^{30}$ AHSVCS, caja 066.

${ }^{31}$ ROS GONZÁLEZ, Francisco S.: Noticias de escultura..., op. cit., p. 503.

${ }^{32}$ Ibidem, pp. 246-49.

${ }^{33}$ ROS GONZÁLEZ, Francisco S.: "Algunas noticias sobre el tallista José Mayorga y el escultor Juan de Astorga", Laboratorio de arte, 20, 2007, pp. 297-298.

${ }^{34}$ Ibidem, pp. 298-300.

${ }^{35}$ Ibid., p. 296.
} 
Cristo, y a sus pies junto al sagrario dos repisas para sendos ángeles, mientras que de los otros dos retablos menores sólo dice que se hallaban compartimentados por pilastras ${ }^{36}$. En cuanto a la ubicación exacta de estos últimos, ambos estaban colocados en el lado de la epístola, el de la Virgen en el primero de los tres tramos de que constaba la nave, y el de la Santa Cruz en el tercer tramo. Añade este autor que cuatro ángeles se disponían en las paredes sobre peanas, las mismas que había realizado Mayorga en 1834, así como que los retablos no llegaron a dorarse ni policromarse, si bien este extremo no nos consta a nosotros con certeza. La descripción que hace Bermejo nos permite deducir que el estilo de los tres retablos respondía a la pureza de líneas propia del estilo neoclásico, tallados en madera para ser policromados imitando jaspes y doradas las basas y capiteles de las columnas, y desprovistos de cualquier concesión al efectismo. El uso en ellos de columnas y pilastras corintias recuerda los retablos realizados en aquellos mismos años en esta ciudad por Juan de Astorga, y concretamente el retablo mayor que hizo Mayorga para la Vera Cruz parece que era de estructura muy semejante a los que Astorga había tallado pocos años antes para la iglesia parroquial de San Miguel y para la capilla de Jesús Nazareno ${ }^{37}$, con un diseño estereotipado que a su vez procedía del retablo de la capilla de San José de la catedral hispalense (1799-1805).

Las obras de reconstrucción de la capilla de la Vera Cruz concluyeron a comienzos del año 1840, siendo consagrada durante la fiesta que la hermandad celebró el día 3 de mayo $^{38}$. Pero el infortunio que desde comienzos del siglo la perseguía, se haría presente de nuevo cuando en el otoño de aquel mismo año la Junta Provincial y el Ayuntamiento de Sevilla acordaron la demolición de lo que restaba del convento de San Francisco, aprovechando la circunstancia de que su comunidad hacía cinco años que había sido exclaustrada, con el fin de abrir una nueva plaza en su amplio solar, en línea con las nuevas tendencias urbanísticas (Figura 1). Con tal motivo las autoridades dieron un plazo de un mes a las hermandades que aún se hallaban allí radicadas para que se trasladasen a otros templos. Ello supuso la pérdida definitiva de la capilla de la Vera Cruz, que fue demolida junto al resto del convento en los últimos meses de $1840^{39}$. No obstante, como las citadas hermandades solicitaron una lógica compensación económica por ello, cada una de ellas encargó al arquitecto Balbino Marrón el

${ }^{36}$ BERMEJO Y CARBALLO, José: Glorias religiosas de Sevilla, op. cit., pp. 362-63.

${ }^{37}$ ROS GONZÁLEZ, Francisco S.: "Los retablos de Juan de Astorga", Laboratorio de arte, 17, 2014, pp. 288-301.

${ }^{38}$ GONZÁLEZ DE LEÓN, Félix: Noticia artística de todos los edificios públicos, sagrados y profanos de esta Muy Noble, Muy Leal, Muy Heroica e Invicta ciudad de Sevilla, y de muchas casas particulares. Sevilla, 1844 (ed. Sevilla, 1973), p. 59.

${ }^{39}$ GUICHOT Y PARODY, Joaquín: Historia de la ciudad de Sevilla. Sevilla, 1882, pp. 665-666. 
reconocimiento de su capilla y su valoración económica, y en el caso de la de la Vera Cruz la visita se realizó el día 4 de noviembre, siendo valorada en 160.240 reales $^{40}$. El correspondiente documento que incluimos en el apéndice nos sirve en primer lugar para contar con una descripción fiable aunque somera de la remozada capilla, de la que el arquitecto afirma que tenía dos naves, a diferencia de lo descrito por los autores contemporáneos ya mencionados, interesante noticia que quizá indique que por entonces se habría podido incorporar a la misma alguna de las capillas vecinas. Y además permite documentar una de las primeras intervenciones profesionales de Balbino Marrón (1812-1867) en la ciudad de Sevilla, en la que aún no había tomado posesión de su cargo como arquitecto municipal, algo que no ocurriría hasta el año $1846^{41}$, siendo así que en calidad de tal y a partir de 1852, se encargaría de llevar a cabo el proyecto de la nueva plaza que se levantaría en el solar que había ocupado el convento de San Francisco, cuyo patrimonio artístico se dispersaría por diversos templos de Sevilla y de otros lugares, entre ellos la iglesia del extinguido colegio carmelita de San Alberto, donde encontraría acomodo desde entonces la hermandad de la Vera Cruz ${ }^{42}$.

\section{APÉNDICE DOCUMENTAL}

\section{Documento 1}

AHSVCS, caja 049, Cuenta que da Pedro Vidal por el dorado del retablo de la Inmaculada Concepción, 28-3-1788.

"Quenta del costo que ha tenido el dorado y pintado del Retablo de Nra. Sra. de la Concepción que se venera en la Capilla de la Sta. Vera Cruz del Convento de Sr Sn Francisco casa grande de esta Ciudad.

Primeramente de aparejos, colores, andamios y barnices, 893. It. de 230 Libros de Oro a precio de onze rs, 2.530. It. del trabajo de los oficiales y mío, quitar andamios, varios portes o mandados, plateado de dos atriles, pintar y dorar dos candeleros, una cruz de madera y su plateado, 2.800. Por manera que importa todo los figurados seis mil doscientos veinte y tres rs. de vn. los mismos que he invertido en las distribuciones de las partidas que quedan sentadas hasta dexar dho

${ }^{40}$ AHSVCS, caja 071

${ }^{41}$ SUÁREZ GARMENDIA, José Manuel: Arquitectura y urbanismo en la Sevilla del siglo XIX. Sevilla, 1986, pp. 99-104; y LINARES GÓMEZ DEL PULGAR, Mercedes: Balbino Marrón y Ranero. Arquitecto municipal y provincial de Sevilla (1845-1867). Sevi1la, 2016, p. 24.

42 AMORES MARTÍNEZ, Francisco: "El patrimonio artístico de la hermandad de la Vera Cruz en la iglesia de San Alberto, y otras noticias de su exilio decimonónico", Boletín de las Cofradías de Sevilla, 530, 2003, pp. 232-34. 
retablo enteramente concluso a toda satisfazión, como en el mismo se demuestra, según mi leal saber. Y para que conste firmo la presente en Sevilla a 28 de Marzo de 1788. Pedro Vidal [firma]."

\section{Documento 2}

AHSVCS, caja 087, Cuenta de la colocación del nuevo retablo de la Virgen del Rosario, 31-10-1794.

"Cuenta del costo que ha tenido la colocación del Retablo de Ntra. Sra. del Rosario que se comisionó por la Junta de Hacienda a los Sres. Dn. Manuel Paulín Moreno y Dn. Vicente Calonge.

Por la cuenta del Maestro Josef González de quitar el retablo viejo y colocación del Nuevo,1.394 rs. Por los dos pedazos que se añadieron de la Guarnición de la Capilla, 120 rs. Por otra cuenta $n^{\circ} 2$ del mtro. Talabán de componer el hueco, 191 rs. Por otra cuenta de hacer el Repisón de madera del mtro. Carmona, 320 rs. Por dorar dho. Repisón y darle color de Piedra, 320 rs. Por estofar los pedazos añadidos de moldura y dorado, 180 rs. Rosario para la Virgen y su engarce, limpiar el de la Señora Antigua, 3 varas de ule a 11 rs. de vn., 8 varas de lienzo para manguitas de cornialtares a 11 rs., 6 varas de encaxe para un mantel a 4 rs., hechura de dho mantel, crudo y ule, tres varas de crudo a 6 rs. de vn., cinta para el ule; retocar la Virgen del Rosario, Sn Francisco y Sto. Domingo, 294 rs. Importan las expresadas partidas dos mil ochocientos y veinte reales de vellón, los mismos que hemos resivido de la Dotasión de Nuestra Señora del Rosario. Sevilla y Octubre 31 de 1794. Manuel Paulín Moreno [firma]. Vicente Calonge [firma]."

\section{Documento 3}

AHSVCS, caja 066, Pliego de condiciones que da José Mayorga para la hechura de tres retablos en la capilla de la Vera Cruz, 14-5-1834.

"Digo yo José Mayorga, altista Ensamblador de esta Ciudad de Sebilla, abel presentado dos diseño para tres retablo que se an de colocar en la capilla de la bera crus situada en la casa grande de San Francisco, y abiendo dado presio de quatro mil y quinientos reales por el mayor y los dos pequeño, que es lo último que llo puedo aserlo, todo como demuestra en los diseño; siendo la medida del mayor ocho bara y media de alto y sinco bara de ancho, con dos repisa a los lado para colocar dos ángeles, las medida de los pequeño es seis bara de alto y quatro de ancho; siendo todo echo de madera de flande buena y seca, con los grueso que corresponde a su tamaño y altura; debiendo ser de calgo de la elmandad los polte y albañilería que ocurra para su colocasión; su pago debe de ser en tres telsio a el comensal la obra y a la emediasión y el último telsio quando esté colocada en su sitio. Todo lo referido prometo el cumplirlo con el favor de Dios; siempre que lo señore de la Junta tenga a bien y sean gustoso que llo aga dicha obra; y quedo 
obligado en esmeralme todo lo que esté de mi parte; el tiempo que nesesito para asel la obra serán de quatro mese para no presipitarla y pódela aser con algún desaogo; es quanto tengo que esponer y quedado obligado; y Usías dispondrán lo que tenga a bien, con su selvidor Mayorga. Sebilla 14 de Mayo de, 1834. José Mayorga [firma]."

\section{Documento 4}

AHSVCS, caja 066, Recibo que da José Mayorga por la talla de tres retablos para la capilla de la Vera Cruz, 22-11-1834.

"Recibí del Sr. Dn. Juan Calonge, como mallordomo de la Elmandad de la Bera Crus, situada en el combento casa grande de Sn. Francisco de esta Siudad, la cantidad de sinco mil quatrosientos noventa y seis reales de Bellón; total de tres retablo y la composisión del mayor y sinco peana para la Birgen y ángeles y mandado de dicho Retablo; todo lo dejo echo y acabado en la Capilla de dicha Elmandad; y para que conste lo filmo en Sebilla a 22 de Nobiembre del año 1834. José Mayorga [firma]".

\section{Documento 5}

AHSVCS, caja 071, Reconocimiento y tasación de la capilla de la Vera Cruz por el arquitecto Balbino Marrón, 4-11-1840.

"D. Balbino Marrón y Ranero Arquitecto de la Academia Nacional de S. Fernando, mtro. mayor de obras públicas de la Ciudad de Jerez de la Frontera.

Certifico: haber visto, reconocido medido y tasado por disposición de los Sres. Mayordomos de la Hermandad de la Vera Cruz la Capilla que pertenece a la misma, situada en el Convento de S. Francisco de esta Ciudad: la cual forma una figura irregular de doce lados en su planta baja, distribuida en dos naves, sacristía, patio, jardín, sala para guardar el paso, y escalera a la Sala Capitular. Su área, consta de ochocientas setenta y cuatro varas cuadradas de terreno. Su material construcción pende en el vaciado de zanjas, para los cimientos, en el relleno de ellos al estilo del País, fábrica de ladrillo, maderamen de pino Flandes, techumbres pobladas de tabla y teja, que con el herrage de gradas y columnas de mármol, agua del jardín, puertas, ventanas y demás que le corresponde, asciende su valor a la cantidad, ciento sesenta mil doscientos cuarenta rs. de vn. Sevilla Noviembre 4 de 1840. Balbino Marrón y Ranero [firma].”

Fecha de recepción: 23 de septiembre de 2017

Fecha de aceptación: 12 de abril de 2018 


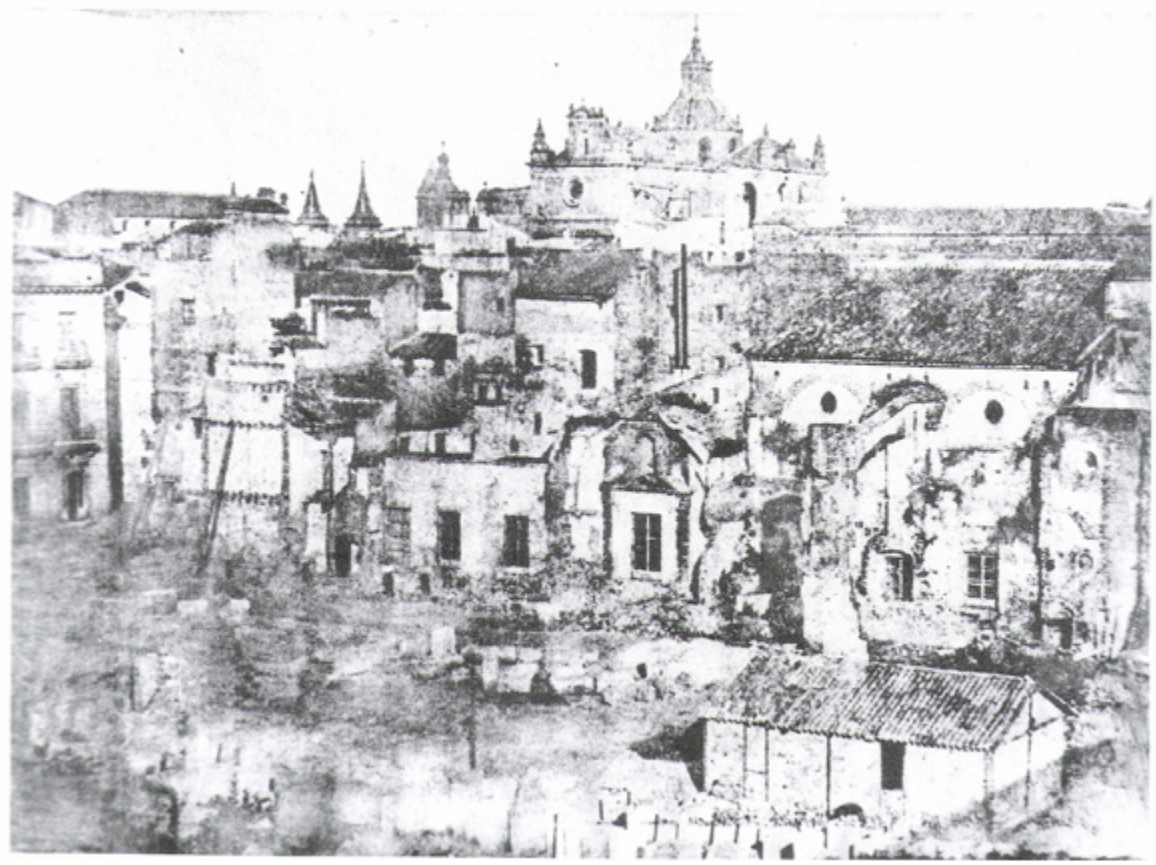

Figura 1. Histórica fotografía del derribo del convento casa grande de San Francisco de Sevilla en 1841. Foto: Francisco de Leygonier. 